\title{
Perceptions of menopause and aging in rural villages of Limpopo Province, South Africa
}

\author{
Authors: \\ Nditsheni J. Ramakuela \\ Henry A. Akinsola ${ }^{1}$ \\ Lunic B. Khoza ${ }^{1}$ \\ Rachel T. Lebese ${ }^{1}$ \\ Augustine Tugli ${ }^{1}$

\section{Affiliations:} \\ ${ }^{1}$ School of Health Sciences, \\ Department of Advanced \\ Nursing Science, University \\ of Venda, South Africa
}

\section{Correspondence to:}

Nditsheni Ramakuela

Email:

nditsheni.ramakuela@

univen.ac.za

\section{Postal address:}

Private Bag X5050,

Thohoyandou 0950,

South Africa

Dates:

Received: 12 Aug. 2013

Accepted: 05 May 2014

Published: 13 Nov. 2014

How to cite this article:

Ramakuela, N.J., Akinsola,

H.A., Khoza, L.B., Lebese,

R.T. \& Tugli, A., 2014,

'Perceptions of Menopause and aging in rural villages

of Limpopo Province, South

Africa', Health SA Gesondheid

19(1), Art. \#771, 8 pages.

http://dx.doi.org/10.4102/

hsag.v19i1.771

\section{Copyright:}

(C) 2014. The Authors.

Licensee: AOSIS

OpenJournals. This work

is licensed under the

Creative Commons

Attribution License.
Background: The term 'menopause' is derived from the Greek words men (month) and pausis (a cessation, a pause). It is a direct description of the psychological and physical events in women where menstruation ceases to occur. It is the time in a woman's life when she has experienced her last menstrual bleed. Menopause is not a disease per se but a condition associated with hormonal changes where oestrogen diminishes to a low level, causing agingrelated health problems.

Objectives: The purpose of this study was to explore perceptions of menopause and aging amongst women in rural villages of Vhembe District in Limpopo Province, South Africa.

Method: The study was qualitative and explorative, using phenomenological approach. Purposive sampling was used to select the four villages and to select the focus groups. Sample size was determined by data saturation.

Results: The study findings were that participants in the villages associated cessation of menstruation to aging rather than menopause. Once menstruation stopped, one was regarded as old.

Conclusion: The conclusions of the study were that (1) menopausal issues should be emphasised and receive priority from puberty at the girls initiation schools, high schools, churches, other community resources and health care services so that when women reach menopause, (2) they should accept and be able to effectively cope with menopause and aging. (3) Emphasis should also be placed on menopause as the aspect of human aging.

Agtergrond: Die term 'menopouse' is afgelei van die Griekse woorde menos (maand) en pausis (onderbreking/pouse, einde) en is 'n direkte beskrywing van die psigologiese en fisiese gebeure in vroue waar menstruasie ophou voorkom. Dit is die tyd in 'n vrou se lewe wanneer die laaste menstruele bloeding ervaar word. Menopouse is nie ' $n$ siekte per se nie, maar ' $n$ toestand wat geassosieer word met hormonale veranderings waar estrogen afneem tot ' $n$ vlak wat gesondheidsverwante probleme veroorsaak.

Doelstelling: Die doel van die studie was om persepsies ten opsigte van menopause en veroudering onder landelike vroue in die Vhembe-distrik in Limpopo Provinsie, Suid-Afrika, te verken.

Metode: Die studie was kwalitatief en verkennend, met ' $\mathrm{n}$ fenomenologiese benadering. Doelgerigte steekproefneming is gebruik om die vier dorpies en deelnemers van die fokusgroepe te selekteer. Die steekproefgrootte is bepaal deur dataversadiging.

Resultate: Die bevindings was dat die deelnemers die einde van menstruasie aan ouderdom, en nie aan menopause nie, toeskryf. Wanneer menstruasie stop, word 'n vrou dus as oud beskou.

Gevolgtrekkings: Aanbevelings was dat (1) menopausale onderwerpe reeds beklemtoon behoort te word vanaf puberteit in inisiasieskole, hoërskole, kerke en gemeenskappe en gesondheidsdienste sodat, wanneer menopouse bereik word, (2) vroue dit kan aanvaar en positief ervaar. (3) Klem behoort ook op menopause as 'n menslike aspek van veroudering gelê te word.

\section{Introduction}

Menopause, in many parts of the world, is regarded as being a major event in a woman's life. Normally and naturally, all women all over the world, regardless of culture and country of origin, will experience menopause and aging should they live to that point in their lives. Menopause is a condition designed by nature and regarded as a normal part of aging; it should not be taken as some sort of disorder or ailment (Ramakuela, Khoza \& Akinsola 2012a:240; Vanda 2003:1). Most women experience menopause around the age of $45-50$ or before; the usual range is between 45 and 55 years. At this age, the woman is at the perimenopausal stage of menopause. Menopause 
and aging changes begin in the female reproductive system when the levels of the main reproductive hormones, namely oestrogen and progesterone, decline to a functional deficiency. It is thus evident that menopause is part of the aging process (Chedraui et al. 2007:271; Ho et al. 2003:149; Lobo:2012; Vanda 2003:1).

The term 'menopause' is derived from the Greek words men [month] and pausis [a cessation, a pause] and is a direct description of the psychological and physical events in the life cycle of women, where menstruation ceases to occur, that is to say, when a woman has experienced her last menstrual bleed (Ramakuela et al. 2012b:265). Menopause is regarded as being a natural transitional period toward permanent infertility in women (Kakkar et al. 2007) and also represents a passage from the reproductive to the post-reproductive life stages. It is regarded as being a useful predictive risk marker for a variety of aging-related diseases and/or health problems and also signals the end point of a woman's menstrual journey. In addition, it signals continuous further change in the bodies of older women as many of these women are symptomatic (Akinrogunde 2010:1). Menopause and aging begin at midlife and are not an easy transition for many women. These are not always changes that women are ready to accept. Menopause and menopause transition are not diseases per se, but are rather a transitional phase of life that reduces health-related quality of life amongst women (Kilaf \& Kirchengast 2008:2).

According to Berger and Wenzel (2001), the process of aging in women:

has a clear social and cultural indicator - menopause. The social construction of menopause [is] the entry point to old age [and] represents a challenging and often difficult time, because, while women may feel rather young and full of energy, society tends to perceive them as becoming increasingly less attractive and less fully functioning. (p. 16)

The time of menopause is characterised by a series of losses that are all associated with aging, such as loss of youth, beauty and fertility, changes in health and a down-regulation of hormones which leads to decreased femininity and calcium levels. These symptoms could have an impact on the physical and psychological well-being of midlife women (Bachmann 1994:113; Brown 1976:109; Buck \& Gottlieb 1991:41; Eden \& Wylie 2009:385; Howard \& Kelly 1994:18; Kaiser 1990:430).

Soules et al. (2001:874) indicate that most normal women will progress from one stage of menopause to the next whilst acknowledging that not all healthy women will follow the same pattern. Furthermore, it is commonly acknowledged that there are considerable hormonal fluctuations underlying the period of menopause, but no biochemical measurement has been considered acceptable as being a precise marker of menopause. As a result, menstrual variables have become the most useful means of gauging a woman's menopausal status in a staging system. However, during menopause, the body undergoes three different phases namely premenopause, perimenopause and post-menopause or menopause
(Ho et al. 2003:149; Ramakuela et al. 2012a:241). Premenopause is a state when a woman is still having menses or menstruated within the last three months. Perimenopause is where the woman has menstruated within the last 12 months and is divided into early perimenopause (defined by unpredictable or irregular menses) and late perimenopause (cessation of menses for at least three months within the previous 12 months, but not as a result of hysterectomy, oophorectomy or pregnancy). Post-menopausal status or menopause is defined as those women whose menstruation has ceased for at least 12 months (Frohlich et al. 2000:35; Ho et al. 2003:149; Mansfield et al. 2004:220; Orner 2005:1; Ramakuela et al. 2012a:241).

At menopause, various changes occur: the ovaries stop ovulating, becoming less active with regard to the production of sex hormones; menstruation stops over a period of several months with intermittent profuse bleeding; and the blood levels of oestrogen and other female hormones decrease, causing menopausal problems. At this stage, menopause should be considered a time of adaptation and transition to a new biological situation that involves loss of the reproductive function. It is a necessary stage that all females must go through from middle adulthood (Bosworth et al. 2003:32; Ramakuela et al. 2012a:241.

Chedraui et al. (2007:271), as well as Ramakuela et al. (2012a:241), observe that during perimenopause, the body still produces some oestrogen whilst progesterone production declines over the years, leading to this change in a woman's body. Women experience water retention, weight gain, memory loss, irritability and depression. During menopause, decreased oestrogen levels may cause bladder and vaginal atrophy. Vaginal walls become drier and thinner, leading a woman to have less interest in sex or slower arousal time. The hormonal changes also disrupt the delicate acid and/or alkaline balance of the vagina which can lead to increased susceptibility to yeast and bacterial infections. Women may also develop fibrocystic breasts, breast cancer, fibroids or endometrial cancer as a result of oestrogen deficiency. Before actual menopause, gradual changes, such as a decrease in the amount of menses, a lengthening of the interval between menses, periodic amenorrhoea and, finally, spotting, occur. These changes create a very unpleasant hormonal imbalance, causing the physical and psychological symptoms of menopause and marking the end of a woman's reproductive capacity (Ho et al. 2003:149; Ramakuela et al. 2012a:241).

\section{Problem statement}

There is a huge difference in the perception of the symptoms of menopause and aging amongst individuals and across cultures, because of cultural beliefs and the manner in which symptoms are perceived and accepted (Bosworth et al. 2003:32). In rural villages, menopause is determined as a result of cultural beliefs, it is often taboo, private and a sensitive topic to discuss amongst villagers. Limpopo Province is one of the most disadvantaged and under-resourced provinces in the country. It is characterised by high levels of poverty 
and illiteracy (Madi \& Hadzhi 2009; Ramakuela et al. 2012a:241). Menopausal women in this province face major challenges as far as menopause- and aging-related issues are concerned, resulting from cultural beliefs, lack of knowledge and information. One of the challenges that is mostly not discussed involves sex at menopause and aging. There is also paucity of data concerning menopause- and aging-related issues, especially amongst rural women in Vhembe District of Limpopo Province.

\section{Aim of the study}

The aim of this study was thus to explore the perceptions of menopause and aging amongst rural women in Vhembe District of Limpopo Province.

\section{Research question}

The following question was posed: What are the perceptions of menopause and aging amongst women aged 40 years and above in rural villages in Vhembe District of Limpopo Province?

\section{Research objectives}

To explore the perceptions of menopause and aging amongst women aged 40 years and above in rural villages in Vhembe District of Limpopo Province.

\section{Research method and design Study designs}

The study design is the researcher's overall plan for obtaining answers to the research questions or to test the hypothesis (Polit \& Beck 2010:259). The study was qualitative and explorative using a phenomenological approach involving menopausal women of 40 years and above residing in rural villages in Vhembe District of Limpopo Province, South Africa. Qualitative research is a way of gaining insight through the discovery of meaning. It is a means of 'exploring the depth, richness and complexity inherent in phenomena' (Burns \& Grove 2009:51). The qualitative approach was important in this study as little was known about the perceptions of menopause and aging amongst the rural women being studied. A phenomenological approach was utilised in order to obtain descriptions of the lived human experiences of menopausal women.

\section{Population}

Population is referred to as the entire group of people that meet a designated set of criteria (Burns \& Grove 2001:368; De Vos et al. 2011). The study population comprised all women between the ages of 40 years and above residing in rural villages. The target population is the entire population or set of individuals in which the researcher is interested and wishes to use to generalise the results of the study (De Vos et al. 2011:116; Ramakuela et al. 2012a:242). In this study, the target population comprised women between the ages of 40 years and above who resided in the rural villages of Mutale. An accessible population is that portion or part of the target population to which the researcher has reasonable access. The population was accessible to the researcher as a pool of participants for the study (Burns \& Grove 2005:341; Polit \& Beck 2010:305). In this study, the accessible population was made up of those participants who came to the arranged venues to form part of the focus group discussions. Inclusion criteria were women aged 40 years and above who resided in the selected villages.

\section{Sample and sampling}

Sampling refers to the process of selecting a portion or subset of the population to represent the entire population. It includes selecting groups of people, events, behaviours or other elements with which to conduct a study. Researchers usually work with samples rather than the whole population as it is more economical and practical to implement in order to obtain reasonable information from the sample (Burns \& Grove 2009:343; Polit \& Beck 2010:307). In this study, a representative portion of the population of women aged 40 years and above was selected purposefully for the focus group interviews, with subjects known to be knowledgeable about menopausal issues. The four villages with the largest population were also selected purposefully for participants in the study. Sample size was determined by data saturation in the fourth focus group.

\section{Data collection}

Focus group interviews were chosen as being the appropriate method of data collection for this study. Krueger (1994:6) defines a focus group as 'a carefully planned discussion designed to obtain perceptions on a defined area of interest in a permissive, non-threatening environment' free from interruptions. Four focus group interviews were conducted by the researcher in order to determine perceptions of menopause and aging among rural women. Focus group interviews promoted self-disclosure and were able to discern what women really thought and felt. Each focus group comprised six to eight women and lasted for approximately 60 minutes. The groups were small enough to provide all participants with the opportunity to share their insights related to the phenomenon, but also large enough to provide sufficient diversity of perceptions. Interview dates were arranged with the contact people and focus group discussions were conducted at the chosen venues. The arrangements were made by telephone conversation with the contact people and then by follow-ups in writing to the tribal office. A central question was asked during the interviews in order to stimulate the discussion, namely, 'Please tell me your perceptions regarding menopause and aging'. Probing questions followed after each response from the participants until saturation was reached. The participants were encouraged to explain the perceptions in their own language, which was Tshivenda. The conversation was free flowing, but was limited to menopause and aging. Data were tape-recorded and transcribed verbatim into English and field notes were used to augment the data recorded. 


\section{Data analysis}

Data were analysed using Tesch's open coding method in Creswell (2003:156). Field notes were written down during data collection, as the participants were talking. Taperecorded interviews were transcribed verbatim into English and the data were then analysed and clustered into themes, categories and subcategories.

\section{Ethical considerations}

The nature and scope of the study were explained to the participants and heads of households and informed consent was obtained. Approval for the study was granted by the Department of Health and Social Development, Tribal Authority and the ethics committee of University of Venda before data collection (project no. SHS/11/PDC/004). Participants were protected from all forms of harm resulting from humiliation or embarrassment, physical discomfort or emotional stress. Privacy was also maintained throughout the study and information was not to be shared without the participant's knowledge (De Vos et al. 2011:116; Polit \& Beck 2008:177; Ramakuela et al. 2012a:243).

\section{Trustworthiness}

The following criteria were used in order to ensure trustworthiness: credibility, dependability, transferability and confirmability. These were maintained throughout the study (Babbie \& Mouton 2009:281).

Credibility was achieved by means of attaining confidence in the data and interpretation thereof. It was thus ensured by the performance of member checks, where the researcher interviewed participants until data saturation. Prolonged engagement was ensured through rapport with participants for about one hour, use of the participants' own language and the researcher staying in the field collecting data until data saturation had occurred. At the end of the focus group interviews, follow-up discussions were conducted in order to verify the data. Literature control was done so as to ensure triangulation of data sources. Field notes and tape recordings were given to an independent coder to check allocated categories and subcategories.

Dependability is the extent to which a study would be consistent should the enquiry be replicated with the same subjects in a similar context under stable conditions over time (Cormack 2000:278; Jooste 2009:322). In this study, participants were purposely selected and an independent coder verified the allocated categories and subcategories.

Transferability was ensured through purposive sampling, collection of detailed information and dense descriptions of the data.

Finally, confirmability was ensured through obtaining valuable information by means of prolonged contact with participants. Confirmability was also ensured by the involvement of the independent coder (De Vos et al. 2011; Ramakuela et al. 2012a:242).

\section{Results}

In this study, focus group interviews were held in order to determine the perceptions of the participants regarding the common challenges associated with menopause and aging. Several challenges were identified by the participants, namely, psycho-social challenges and age, menopausal challenges disrupting normal lives, discrimination and stigmatisation, as well as a lack of support by family and community.

All interviews were treated as being anonymous, with no identifiers being recorded.

\section{Psycho-social challenges and age}

Menopausal participants aged 40 years and above reported being frustrated and very sick because of the severe menopausal challenges coming with age, as well as feeling socially isolated. These findings are supported by the following responses:

'Old age is bad, look at my skin is becoming wrinkled and no longer shiny and firm. You know I used to be very big and fresh and now I have lost weight I look wasted. My breasts were so big and nice, my children would get enough milk from one breast, but now they are so thin with no flesh. My big curves and bums are gone with old age [uttered by a frustrated post-menopausal participant].'

Another perimenopausal participant reported:

'It all started when I aged. I felt joint and back problems later, headache, forgetfulness and memory loss at times. I look terrible and feel wasted, deformed and no longer attractive. Now people think I have mental illness and are reluctant to come near me because I sometimes become irritable to them thus they reject me. I do not do it on purpose; it just happens, you know.'

\section{Menopausal challenges disrupt normal lives}

Participants felt some menopausal symptoms were more troublesome, bothersome and embarrassing and disrupted their normal lives, as described by a post-menopausal participant:

'Our normal lives become disrupted with age-related health problems.'

Through probing she said, pausing and shaking her head:

'Ho! I am referring to severe joint and back pains, urinary frequency, sleeplessness, forgetfulness and depression. Sweat would dripple [sic] down your face when you least expect it even in cold weathers, it is embarrassing to other people who are not used to it. This is like punishment from God, you know [sigh].'

An early perimenopausal participant with bothersome and embarrassing symptoms said:

'I have frequency of urine especially if I have taken too much water. By the time I reach the toilet, part of the urine has come out or coming out and would wet my under wears.'

She looked down then continued to say: 
'It is quite embarrassing when you smell of urine and each time you are from the toilet your clothes are wet with urine. I do not like smelling urine at all and because I have frequency I usually bathe twice a day, in the morning when I go to work and immediately I am [home] from work.'

\section{Discrimination and stigmatisation}

The study findings revealed that although old women receive respect and trust from young women and other people, they still seem to be discriminated against and are stigmatised by others, as evidenced by a frustrated late perimenopausal participant with bothersome and embarrassing symptoms:

'There are some young children and other people in the village who do not care about you when you are old. I stay alone in my house and never had children of my own. I am sick all the time for over two years now. Only neighbours sometimes assist me with cleaning the house, cooking food and giving me treatment other people discriminate me.'

One of the post-menopausal participants also said:

'It is difficult when you are old and cannot help yourself. This illness is frustrating us as even if you get support from family members, they get tired of helping you all the time. They would say that gegulu li a dina, meaning that old lady is troublesome. When they start doing that I feel isolated. I even lost sight and my hearing has diminished and I would not hear for a long time, especially on waking up in the morning.'

\section{Lack of support}

Some participants experienced a lack of support from their family members and other villagers, whilst others obtained some information from family members like grandmothers and colleagues about what they were experiencing, as was illustrated by an early perimenopausal participant:

'I stay with my mother-in-law. She is now very old and in my entire stay with her I never heard her make mention or discuss about it. She used to tell me about all other things but menopause is a taboo.'

Another participant added:

'At the girls' initiation when we were still young, old women told us blood will cease and since then no one ever talked to me about it that is why I say it is my secret.'

Through probing she said:

'No, I don't remember much, but they do not tell us many things, only what I said just now.'

A post-menopausal participant who still looked attractive said:

'My husband knew that if we continue having sex at this age, he might invite trouble for me and my tummy will bulge and I might die and my family might be angry with him. Family and community members do not support sex at old age; it is taboo.'

\section{Discussion}

\section{Psycho-social challenges and age}

The majority of participants expressed a feeling of selfdevaluation, a feeling of social isolation and the fear of no longer being attractive, as well as fear of old age and dying as a result of severe menopausal challenges and aging. Participants who had a feeling of self-devaluation indicated that they felt that they had lost their self-esteem because of the suffering and deformities associated with aging and menopause. They also felt isolated as they were no longer attractive because of the physical and psychological challenges that had affected their well-being. Their bodies looked wasted and wrinkled and they were in constant bodily pain - to the extent that their family members and some neighbours' thought they were looking for too much attention or were insane. This implies that these menopausal women seemed to be unable to come to terms with the aging process, which is an aspect of human aging that reduces their quality of life. It also implied that these women lacked knowledge and accurate information regarding the topic of menopause and menopausal issues.

According to Ramakuela et al. (2012a:242), midlife transformation represents a changing point for any women to start living life on their own. However, menopause and aging are not always changes that the majority of women are ready to accept and they do not get to choose when these will happen, as menopause occurs when a woman reaches a certain age. Menopause at midlife is not an easy transition for many women.

According to Berger and Wenzel (2001:9), physical changes brought about by the aging process were found to be more readily accepted by Filipino women, who spoke of looking forward to the joys of old age. Being elderly in Filipino society meant being loved and respected by people in general. For instance, it was seen as a privilege for an elderly woman to be offered a seat on public transport and to be addressed politely as 'Madam'. To them, the physical problems were usually of minor concern. It seems as if in this study physical and psychological difficulties were a result of an inability to come to terms with the aging process and were inextricably linked to the socio-cultural environment.

The social construction of menopause is viewed as the entry point to old age and represents a challenging and often difficult time because, whilst women may still feel rather young and full of energy, society has a tendency to perceive them as increasingly less attractive and less fully functioning. The time of menopause is characterised by a series of losses, including loss of youth, beauty, fertility, libido and health. These symptoms may possibly have an impact on the physical and psycho-social well-being of midlife women (Bachmann 1994:1049; Buck \& Gottlieb 1991:41; Howard \& Kelly 1994:18; Kaiser 1990:430). Berger and Wenzel (2001:9) and Ramakuela et al. (2012a:253) indicate that women frequently associate the experience of their aging process with a feeling of selfdevaluation and a fear of no longer being attractive. This often considerably impairs their self-confidence and the mental perception of being a woman. Others fear old age, because they associate it with loss of attractiveness and, as such, they often display negative feelings toward menopause. 


\section{Menopausal challenges disrupt normal lives}

The majority of participants expressed their perceptions of how age-related health problems disrupted their lives. They regarded it as a punishment because of the physical and psychological conditions of aging that occur as a result. Although there was an expression of frustration, almost all post-menopausal and late perimenopausal participants felt that age-related health problems were like punishment from their God. Some perimenopausal participants who were aware of their bodily changes were stressed, afraid, shocked and depressed by these changes. They also indicated that they ignored the changes but could not cope as they affected their daily activities and quality of life. Some became angry with themselves as the symptoms embarrassed them in front of people who were not familiar with the symptoms. Thus they regarded old age as a punishment and frustration because of the severity of the symptoms. The researcher identified a gap of knowledge on the perceptions of menopause and aging as well as the related challenges by rural women, as the aspect of human aging and the relationship of menopause and aging-related challenges.

The issue of aging was mentioned by Berger and Wenzel (2001:9) and Ramakuela et al. (2012a:253) as a problem reported by approximately $25 \%$ of Australian women who found it difficult to come to terms with the aging process and its associated symptoms, such as irritability, depression, fear of aging, loneliness, mood swings, unhappiness, loss of selfesteem and a loss of respect and admiration on the part of others. Baig and Karim (2006:71) and Liu and Eden (2007:359) identified that the menopause- and aging-related symptoms amongst Pakistani women included lack of sleep, urinary incontinence associated with adverse marital problems and poor education, depression, mood swings and loss of selfesteem (Life Research Universal 2007).

\section{Discrimination and stigmatisation}

The findings of these studies revealed that although old women receive respect and trust from young women and other people, they still seem to be discriminated against and are stigmatised by others. In the rural villages, elderly people, in spite of their sex or age, still seem to be trusted, respected and receive special attention from community members; they are still regarded as being important veterans who deserve respect and special attention. However, there were still people who addressed them as gegulu which, translated literally, means 'that old woman'. They were addressed or referred to as old women who were old, sick and useless because of their condition and were regarded as being both physically and mentally unstable. Old women who were also seen to misbehave in the community by either drinking alcohol or being promiscuous, lacked respect and trust in the community. Later in their lives, when they became sick, they were discredited, discriminated against, labelled and stigmatised. This implied a lack of adequate information regarding the perceptions of menopause, aging and menopausal issues.
The issue regarding menopausal women is as old as mankind. As far back as 1991, Graves (1996) indicated that:

few women have observed specific incidents of direct discrimination against menopausal women, although many acknowledge a work environment that diminishes them with daily demeaning [behaviours] and joking at their expense.

Herek (1999:1106) describes stigma as a state of prejudice, discounting, discrediting and discriminating that often results in stereotyping and labelling.

Graves (1996) posits that 'women who decide to make a new life from their menopause begin by educating themselves. They read books, seek good medical advice before making decisions, talk to other women and perhaps to a therapist. In general, these women feel surer of themselves and are more assertive than ever before'. Many say they feel freer and more content than at any other time in their lives.

\section{Lack of support}

It was indicated in the focus groups that parents and grandparents contributed a great deal to the sexuality of the youth. Not much was mentioned regarding menopause even though their contributions were both positive and negative. However, the majority of the participants provided mainly negative contributions. The participants who mentioned positive contributions from their parents or grandparents were those who indicated that they were told that menstruation will cease one day and it was natural. It would seem that family members had difficulties with regard to stimulating discussions around the issues of menopause. When elders talked about menopause it would be when they talked about avoiding sex at the menopausal stage. Further than that, no information was provided. The above comments indicate a deficiency in the parent-child or grandparent-child relationship regarding menopausal issues. The deficient relationships later impacted negatively on the lives of menopausal participants as they had a negative attitude toward menopausal symptoms.

It also evident that some menopausal participants were bound to have a negative attitude toward menopause because of the influence of their parents or grandparents, who were not open enough to discuss menopausal issues with them. It also meant that there was no openness and transparency amongst parents, grandparents and menopausal participants, which would have allowed them to enhance their self-confidence and self-esteem. Participants also indicated that they were unable to receive social support from traditional family members in order to discuss issues of sex at menopause and aging both openly and honestly. The only social support that they received involved myths around sex and sexual issues. The researcher thus realised that every ethnic group, tribe or nation has a belief system which determines and shapes the lives and everyday activities of its members. Thus, menopause and aging were seen as not forming part of the discussions in families and communities because of the belief systems of that ethnic group in those villages under study. 
Furthermore, it shows a lack of openness and trust amongst grandparents, parents and daughters which cannot lead to a good relationship and boost self-confidence. Some participants who were married indicated that they also lacked family support as they did not discuss such topics with their husbands. It would seem that these men were told by their elders to stop having sex with their wives at a certain stage in order to prevent them from developing a bulging tummy. Thus the participants would just see their husbands staying away from them without prior discussions. It would seem that these men do not want to be blamed should their wives develop bulging tummies or die as a result of sex at old age. Such women would not even ask the elderly women in their families about their husbands staying away from them at menopause and aging. Rumours that already prevail in the villages forbid these women to practise sex at menopause as this could result in them developing bulging tummies. This implied that women going through menopause and aging in the villages lacked social support, both from the families and the communities. These participants were also not assertive enough to talk about their feelings or to feel that they have the right to receive adequate information from elderly women in their families and communities.

The traditional ways of sharing information and knowledge in many rural families and communities have been destabilised (Maluleke 2001; Ramakuela et al. 2012a:242). According to Orner (2005:1), women from rural communities lack resources such as libraries, bookshops or supermarkets where they can obtain materials which would have information on menopause. Whilst they might be able to obtain such information from municipal or university libraries in big cities, such facilities are usually far from their communities.

Men practise polygamy as a natural way to quell their sexual appetites once their main wives have reached menopause. The diverse cultural perceptions of menopause amongst menopausal women might be influenced by diet, environment, cultural beliefs (myths) and genetics (Berlin 2009). In this context, men practise polygamy because of the myths prevailing in the families and communities as a way of protecting their wives from developing bulging tummies. It would imply that husbands and wives, elderly women and men, other family members and the whole community lack adequate knowledge and information regarding menopause and aging issues.

\section{Conclusion}

The findings of this study revealed that the majority of participants in the rural villages held negative perceptions regarding menopause and aging issues as a result of the values and cultural beliefs that prevail in the villages and a lack of information regarding effective coping mechanisms for menopause and the aging process. There was also strong evidence that the majority of participants lacked adequate support from family members, as well as accurate knowledge and information regarding menopause and the aspect of human aging, hence could not make informed choices, even regarding their sexuality, at menopause and aging.

\section{Recommendations}

Workshops should be conducted by the researcher for rural menopausal women in order to empower them through education regarding the subjects of menopause, age and issues surrounding menopause. In the rural villages, menopause is taboo, private and a sensitive topic to discuss amongst villagers. There is a need for some level of sexual education for girls at high schools, as well as orientation and training at young girls' clubs, youth churches and health education programmes for older women on menopause and aging issues in the communities.

\section{Acknowledgements}

We thank all the menopausal women who took part in the study from all the villages involved, as well as the chief, tribal authority and headmen of the villages. The financial assistance received from the University of Venda is also appreciated.

\section{Competing interests}

The authors declare that they have no financial or personal relationship(s) which may have inappropriately influenced them in writing this article.

\section{Authors' contributions}

N.J.R. (University of Venda) was the project leader and was involved in conceptualisation, data collection and data analysis, as well as writing the manuscript. L.B.K. (University of Venda) was responsible for study conceptualisation and proof reading. H.A.A., R.T.L. and A.T. (all University of Venda) were involved in study conceptualisation, data analysis and proof reading.

\section{References}

Akinrogunde, G.T., 2010, 'Menopause, culture and sex', African View on Global News 3, 5.

Babbie, E. \& Mouton, J., 2009, The practice of social research, 12th edn., Wadsworth, Cengage Learning, Belmont, CA.

Bachmann, G.A., 1994, 'The changes before "the change": Strategies for the transition to the menopause', Postgraduate Medicine 95(4), 113-115, 119-121, 124.

Baig, L.A. \& Karim, S.A., 2006, 'Age at menopause, and knowledge of and attitudes to menopause, of women in Karachi, Pakistan', Journal of the British Menopause Society 12(2), 71-74. http://dx.doi.org/10.1258/136218006777525721

Berger, G. \& Wenzel, E., 2001, Women, body and society. Cross-cultural differences in menopause experiences, viewed 08 December 2007, from http://ldb.org/ menopaus.htm

Berlin, E., 2009, Your menopause experience may depend on your cultural background viewed 26 July 2014, from http://www.everydayhealth.com/menopause/ menopause-and-culture.aspx

Bosworth, H.B., Bastian, L.A., Rimer, B.K. \& Siegler, I.C., 2003, 'Coping styles and personality domains related to menopausal stress', Women's Health Issues 13(1), 32-38. http://dx.doi.org/10.1016/S1049-3867(02)00192-5

Brown, M.C., 1976, 'Emotional response to the menopause', in S. Campbell (ed.), The management of the menopause and post-menopausal years, pp. 109-115, MTP Press Limited, Lancaster. http://dx.doi.org/10.1007/978-94-011-6165-7_9

Buck, M.M. \& Gottlieb, L.N., 1991, 'The meaning of time: Mohawk women at midlife', Health Care for Women International 12(1), 41-50. http://dx.doi org/10.1080/07399339109515925

Burns, N. \& Grove, S.K., 2009, The practice of nursing research: Appraisal, synthesis, and generation of evidence, 6th edn., Saunders Elsevier, St Louis, MO. 
Chedraui, P., Aguirre, W., Hidalgo, L. \& Fayad, L., 2007, 'Assessing menopausal symptoms among healthy middle aged women with the Menopause Rating Scale', Maturitas 57(3), 271-278. http://dx.doi.org/10.1016/j.maturitas.2007.01.009

Cormack, D., 2000, The research process in nursing, 4th edn., Blackwell Science, Oxford.

Creswell, J.W., 2003, Research design: Qualitative, quantitative, and mixed methods approaches, 2nd edn., Sage Publications, Inc., London.

De Vos, A.S., Strydom, H., Fouche, C.B. \& Delport, C.S.L., 2011, Research at grassroots for social science and human service professions, 4th edn., Van Schaik, Pretoria.

Eden, J.E. \& Wylie, K.R., 2009, 'Quality of sexual life and menopause', Women's Health 5(4), 385-396. http://dx.doi.org/10.2217/whe.09.24

Frohlich, K.L., Kuh, D.J., Hardy, R. \& Wadsworth, M.E., 2000, 'Menstrual patterns during inception of perimenopause: What are the predictors and what do they predict?', Journal of Women's Health \& Gender-Based Medicine 9(1), 35-42. http://dx.doi.org/10.1089/152460900318939

Graves, B., 1996, Menopause in the trenches, viewed 14 March 2012, from http:/ www.coaching 4 midlife.com/article2.html

Herek, G., 1999, 'AIDS and stigma', American Behavioral Scientist 42(7), 1106-1116. http://dx.doi.org/10.1177/00027649921954787

Ho, S.C., Chan, S.G., Yip, Y.B., Chan, S.Y. \& Sham, A., 2003, 'Factors associated with menopausal symptom reporting in Chinese midlife women', Maturitas 44(2), 149-156. http://dx.doi.org/10.1016/S0378-5122(02)00325-0

Howard, G. \& Kelly, P., 1994, 'Osteoporosis: Strategies for prevention and treatment', Modern Medicine of Australia 37(7), 18-27.

Jooste, K., 2009, The principles and practice of nursing and health care, Van Schaik Publishers, Pretoria.

Kaiser, K., 1990, 'Cross-cultural perspectives on menopause', Multidisciplinary perspectives on menopause, Annals of the New York Academy of Sciences 592, 430-432. http://dx.doi.org/10.1111/j.1749-6632.1990.tb30363.x

Kakkar, V., Kaur, D., Chopra, K., Kaur, A. \& Kaur, I.P., 2007, 'Assessment of the variation in menopausal symptoms with age, education and working/non-working status in north-Indian sub population using menopause rating scale (MRS)', Maturitas 57(3), 306-314. http://dx.doi.org/10.1016/j.maturitas.2007.02.026

Kilaf, E. \& Kirchengast, S., 2008, 'Menopause between nature and culture: menopausal age and climacteric symptoms among Turkish immigrant women in Vienna, Austria', Acta Medica Lituanica 15(1), 2-8.
Krueger, R.A., 1994, Focus groups: A practical guide for applied research, 2nd edn., Sage Publications, New Delhi.

Life Research Universal, 2007, Menopause: Blessing or affliction?, viewed 16 July 2009, from http://www.liferesearchuniversal.com/menopause.html

Liu, J. \& Eden, J., 2007, 'Experience and attitudes toward menopause in Chinese women living in Sydney - a cross-sectional survey', Maturitas 58(4), 359-365. $\mathrm{http}: / / \mathrm{dx}$.doi.org/10.1016/j.maturitas.2007.09.007

Lobo, RA., 2012, 'Menopause and care of the mature woman: Endocrinology, consequences of estrogen deficiency, effects of hormone replacement therapy, treatment regimens', in V.L. Katz, G.M. Lentz, R.A. Lobo \& D.M. Gershenson (eds.) Comprehensive Gynecology, 6th edn., Elsevier Mosby, Philadelphia, PA.

Madi, N. \& Hadzhi, N,.L., 2009, Thulamela Municipality Integrated Development Plan (IDP) review 2009/10-2011/12, Limpopo Province, Vhembe District, South Africa.

Maluleke, T.X., 2001, 'The puberty rites for girls (vukhomba) in the northern region of the Northern Province of South Africa: implications for women's health and health promotion', doctoral thesis, Dept. of Advanced Nursing Sciences, UNISA, Pretoria.

Mansfield, P.K., Carey, M., Anderson, A., Barsom, S.H. \& Koch, P.B., 2004, 'Staging the menopausal transition: Data from the TREMIN Research Program on Women's Health', Women's Health Issues 14(6), 220-226. http://dx.doi.org/10.1016/j. whi.2004.08.002

Orner, P., 2005, Sexuality of older women, Health Systems Trust and Women's Health Resource Unit of the University of Cape Town, South Africa.

Polit, D.F. \& Beck, C.T., 2010, Essentials of nursing research: Appraising evidence for nursing practice, 7th edn., Wolters Kluwer Health, Philadelphia, PA.

Ramakuela, N.J., Khoza, L.B. \& Akinsola, H.A., 2012a, 'Menopausal challenges as perceived by women in rural villages of Limpopo Province, South Africa', African Journal for Physical, Health Education, Recreation and Dance 18, 240-258.

Ramakuela, N.J., Khoza, L.B. \& Akinsola, H.A., 2012b, 'Rural women's understanding of the concept menopause in Limpopo Province, South Africa', African Journal for Physical, Health Education, Recreation and Dance 18, 259-273.

Soules, M.R., Sherman, S., Parrott, E., Rebar, R., Santoro, N., Utian, W. et al., 2001, 'Executive summary: Stages of Reproductive Aging Workshop (STRAW)', Fertility
and Sterility 76(5), 874-878. http://dx.doi.org/10.1016/S0015-0282(01)02909-0

Vanda, H., 2003, Perimenopause vs. menopause: What's the difference?, viewed 08 August 2014, from http://health.howstuffworks.com/wellness/women/ menopause/perimenopause-vs-menopause.htm 